\title{
Autism and Addiction to Video Games?
}

\author{
Jesus Dueñas Becerra* \\ Department of Psychology, Member of the Center for Studies of the Archdiocese of Havana, Cuba
}

*Corresponding author: Jesus Dueñas Becerra, Department of Psychology, Member of the Center for Studies of the Archdiocese of Havana, Cuba.
Received Date: September 16, 2019

Published Date: September 24, 2019

\section{Concept}

Dr. Elsa Gutiérrez Baró (1926-2019), professor emeritus of the University of Medical Sciences of Havana, contacted us, to raise a problem of child-youth mental health that worries her in the highest degree. In recent times, he is seeing in consultation with relative frequency - children and adolescents, who have been diagnosed with autism, because the clinical picture they present evokes the presence of this genetic cause condition. However, autism - as a nosographic entity - has nothing to do with the origin of the symptoms that these patients suffer. Deterioration of interpersonal and social relationships, disinterest in the surrounding environment, affect in the process of flattening, among others no less alarming. Although some of them have points of tangency with which children and adolescents with autism usually suffer, the reality of the patients who are offered specialized care is a very different one. When Dr. Gutiérrez Baró researches her personal and psychosocial pathogenic background, the first thing she perceives is that these patients dedicate several hours a day to video games, where - above all - violence and aggressiveness prevail. Consequently, they forget to go out and play with school or neighborhood classmates, stop attending parties, movies, theater; With one word, they relegate social life to a secondary level. And even, familiar, because some of them eat in front of the computer screen without manifesting any other type of cognitive or spiritual interest, other than the aforementioned video game. It is very important to clarify the fact that neither Dr. Elsa Gutiérrez Baró nor we are against technological development; on the contrary, we are in favor of him, because it is the language of the present, but with the exact dose of moderation. This comment becomes an urgent appeal to parents and teachers to ensure that their children and disciples, without giving up the video game or the magical world of computing, are much more integrated into community life, which is ultimately, what has made homo sapiens human.

\section{Acknowledgement}

None.

\section{Conflict of Interest}

No conflict of interest. 